\title{
СЕМЬЯ В СТРУКТУРЕ ЦЕННОСТЕЙ МОЛОДЕЖИ
}

\author{
Артур А. Реан \\ Национальный исследовательский университет \\ «Высшая школа экономики», г. Москва, Российская Федерачия \\ E-mail: 4885679@gmail.com
}

В статье подчеркивается противоречие между высокой значимостью семьи в структуре ченностей молодежи и большим количеством разводов именно среди молодежи. При анализе этого противоречия делается вывод, что молодежь нужно специально готовить к семейной жизни. Приводятся результаты масштабного эмпирического исследования, проведенного в восьми регионах разных федеральных округов России. Общий объем репрезентативной выборки составил более 7000 человек. Выборку составили респонденты из больщих и малых городов России, а также из сел, из полных и неполных семей, из семей с 1-2 детьми и многодетных семей.

Показано, что в структуре жизненных иенностей молодежи семья занимает первое место. Установлено, кроме того, что подавляющее число респондентов считает наличие семьи обязательным условием счастья. Установлено также, что абсолютное большинство респондентов полагает, что нужно специально готовить человека к созданию семьи. Но только треть опрошенных полагает при этом, что это можно сделать с помощью преподавания специального курса по вопросам семьи и семейной жизни в школах. Показано, что для большинства респондентов их нынешняя, родительская семья не является ориентиром и образцом. Показано, что репродуктивные установки молодежи преимущественно связаны с наличием в будущем двух-трех детей, что не соответствует современной реальной демографической статистике. Выявлено, что более половины респондентов одобрительно относятся к гражданским бракам. Вместе с тем, к рождению детей вне брака отношение молодежи менее терпимое. Установлено, что наибольшее влияние на молодежь в прочессе их взросления оказывает мать. Отиы, занимая второе место, проигрывают матерям с большим разрывом. Выявлено, что обобщенные портреты матери и отиа оказались полностью положительными. То есть, они не содержали ни одной негативной характеристики. Общие качества, которые попали в первую десятку наиболее популярных в описаниях как отиа, так и матери, следующие: добрый, надежный, заботливый, ответственный, семейственный, умный. 
Ключевые слова: семья, ченности, отношение к семье, браки, разводы, репродуктивные установки, портреты родителей, роль отиа, семейная подготовка, семьеведение.

Для цитирования: Реан А. А. Семья в структуре ценностей молодежи // Российский психологический журнал. - 2017. - Т. 14. - № 1. - С. 62-76.

Материалы статьи получены 07.09.2016

UDC 159.9.072.43

doi: 10.21702/rpj.2017.1.4

\title{
A FAMILY IN THE STRUCTURE OF VALUES OF YOUNG PEOPLE
}

\author{
Artur A. Rean \\ Higher School of Economics, Moscow, Russian Federation \\ E-mail:4885679@gmail.com
}

Despite the fact that a family is extremely significant in the system of values of young people, the number of divorces is increasing in this population group. The analysis establishes that young people need to be prepared for family life. The paper presents the results of a large-scale empirical study conducted in eight regions in Russia's various federal districts. The study involved over 7000 respondents from two-parent and one-parent families, as well as families with up to two children and large families; they were inhabitants of Russian large and small cities and villages.

The findings of the study revealed that (a) a family led in the structure of young people's life values. (b) Most respondents believed that a family was a precondition for happiness. (c) Most respondents noted that one should be prepared for family life. (d) Only a third of respondents believed that a school course in family issues could solve this problem. (e) Most respondents noted that their parent families failed to be role models. (f) Young people's reproductive attitudes towards having two or three children did not correspond to modern real demographic statistics. $(\mathrm{g})$ More than half of the respondents approved civil marriages. ( $h$ ) Young people were less tolerant towards births outside of marriage. (i) Mothers had greater influence on young people in their development. (j) The generalized portraits of mothers and fathers were entirely positive (without any negative characteristics). (k) The most popular common qualities of both mothers and fathers were the following: kind, dependable, caring, responsible, domestic, and clever.

Keywords: family, values, relation to family, marriages, divorces, reproductive attitudes, portraits of parents, father's role, family training, family issues course. 
For citation: Rean A. A. A family in the structure of values of young people. Rossiiskii psikhologicheskii zhurnal - Russian Psychological Journal, 2017, V. 14, no. 1, pp. 62-76 (in Russian).

Original manuscript received 07.09.2016

\section{Проблема}

«Семья не является основой общественной жизни. Основой общественной жизни является семья счастливая», - афористично заметил в одном из своих писем знаменитый Артур Конан Дойл [5, с. 74]. Современная семья - счастливая ли она, каково ее место в структуре ценностей молодежи, каково вообще будущее этого института под названием «семья»? В последние годы непрерывно звучат слова о том, что институт семьи в кризисе. Эта мысль озвучивается на различных уровнях - от бытового до научного, и до политического. Значительно возросло количество разводов. По данным Росстата, с 2010 г. число разводов относительно заключенных браков неизменно превышает цифру в 50\%. Так, в 2010 г. эта цифра составляла 52,6\%, в 2011 - 50,9\%, в 2012 - 53,1\%, в 2013 - 54,5\%, в 2014 - 56,5\% [12]. Причем основная масса разводов приходится как раз на первые годы брака и происходит в возрасте 25-29 лет. Примерно на этот же возраст падает и основная доля разводов и в других странах мира, например в США - это 20-24 года [1, 6, 8]. Эта тенденция связывается с заметным ослаблением за последние десятилетия нормативного императива, предписывающего сохранение брака, обзаведение детьми, ограничение интимных отношений рамками брака [20].

Вместе с тем, однако, как показывают многочисленные исследования, семья занимает высоко значимое место в структуре ценностей молодежи $[10,13,15,16]$. Более того, семья, семейные роли и обязанности являются важными компонентами определения самого себя, осознания и представления собственной идентичности [22]. В различных исследованиях было показано, что семья неизменно входит в тройку наиболее важных ценностей молодежи, а во многих исследованиях она занимала собственно первое место.

Так, например, исследования В. Е. Семенова [13] показали, что главными жизненными ценностями молодежи являются семья, друзья, здоровье. Далее следуют: интересная работа, деньги, справедливость. Замыкает семерку главных жизненных ценностей - вера.

В другом исследовании было показано, что «счастливая семейная жизнь» занимает первое место в структуре ценностей старшеклассников. Следующие две позиции занимают ценности «достижение материального благополучия» и «успешная профессиональная деятельность». Правда, в повторном исследовании, проведенном спустя несколько лет, семья как ценность, хотя 
и сохранила свое лидирующее положение, но получила заметно меньше выборов. Если в первом исследовании (1991 г.) семью выбрали 73,5\% опрошенных, то во втором (1996 г.) - уже только 60,2\%. В то время как две другие ценности сохранили не только свои ранговые места, но и получили почти то же (незначительно меньшее) количество выборов [16].

В еще одном исследовании на эту тему, при опросе молодежи, $83 \%$ респондентов, отвечая на вопрос, какими бы они хотели видеть себя через несколько лет, выбрали вариант ответа: «человеком, у которого крепкая семья и хорошие дети» [7].

Ценности детей и родителей, хотя и не идентичны, но вполне согласуются друг с другом. Так, в одном из исследований был проведен сравнительный анализ ценностей детей и родителей (по методике М. Рокича). Оказалось, иерархия их для отцов такова: «здоровье, семья, материальная обеспеченность, любовь, свобода, независимость»; для матерей - «семья, здоровье, любовь, материальная обеспеченность, чувство долга, ответственность». В структуре же ценностей их детей-старшеклассников поднялась значимость ценностей «свобода, независимость», что для психологов, конечно, не является удивительным. Но такие ценности, как «здоровье, любовь, семья» сохранили свои высокие позиции и в этой выборке [17].

Думая о своей будущей семье, строя жизненные планы, молодые люди, естественно, исходят из определенных представлений о своей будущей семье, опираются на ее определенные образы. Исследования показывают, что главным источником представлений о семье молодежь, прежде всего, считает родительскую семью - 53,2\% респондентов. Второе и третье места в этом списке источников представлений занимают мнение друзей - 23,1\% и литература - 21,2\% [7].

Отношение к семье в ходе взросления меняется. В процессе социализации группа ровесников в значительной степени замещает родителей (происходит «обесценивание» родителей - по выражению Х. Ремшмидта [11]). Перенос центра социализации из семьи в группу ровесников приводит к ослаблению эмоциональных связей с родителями. Необходимо заметить, что замечания относительно «обесценивания» родителей в подростковом и юношеском возрастах являются очень распространенными и даже, можно сказать, стали общим местом. Например, для подросткового возраста описана специальная поведенческая особенность «реакция эмансипации». Сделаны даже попытки объяснить ее с эволюционно-биологической точки зрения. Вся эта тенденция, конечно, верна как общее направление возрастного развития личности. Однако глобализация этих представлений, гиперболизация идеи о «замещении родителей» группой сверстников - мало соответствуют реальной психологической картине. 
Имеются данные о том, что хотя родители как центр ориентации и идентификации отступают в этом возрасте на второй план, это относится лишь к определенным областям жизни. Для большинства молодых людей родители и особенно мать остаются главными эмоционально близкими лицами.

Так, в одном исследовании немецких ученых было показано, что в проблемных ситуациях наиболее эмоционально близким, доверенным лицом для подростка, прежде всего, служит мать, а затем, в зависимости от ситуации, в разной последовательности - отец, подруга или друг. В другом исследовании, выполненном на отечественной выборке, старшеклассники ранжировали, с кем они предпочли бы проводить свое свободное время с родителями, с друзьями, в компании сверстников своего пола, в смешанной компании и т. д. Родители оказались у юношей на последнем (шестом) месте, у девушек - на четвертом месте. Однако, отвечая на вопрос «С кем бы ты стал советоваться в сложной житейской ситуации?», и те и другие поставили на первое место мать. На втором месте у мальчиков оказался отец, у девочек - друг, подруга. Иначе говоря, с друзьями приятно развлекаться, но в трудную минуту лучше обратиться к маме [4].

Наши данные, полученные позднее на выборках подростков, юношей и девушек, подтверждают эту тенденцию. Как показано в одном таком исследовании (А. А. Реан, М. Ю. Санникова), в системе отношений личности к социальному окружению (в том числе определялось отношение к обоим родителям и сверстникам) именно отношение к матери оказалось наиболее положительным. Было установлено, что снижение положительного отношения к матери, увеличение негативных дескрипторов (характеристик) при описании матери коррелирует с общим ростом негативизации всех социальных отношений личности.

Можно полагать, что за этим фактом стоит фундаментальный феномен проявления тотального негативизма (негативизма ко всем социальным объектам, явлениям и нормам) у тех личностей, для которых характерно негативное отношение к собственной матери. В целом, как установлено в исследовании, негативное отношение к матери является важным показателем общего неблагополучного развития личности [9]. Нарушение взаимоотношений в системе «мать, отец - дети», как многократно было показано во многих и отечественных, и зарубежных исследованиях, ведет к формированию склонности к деструктивному поведению, агрессии, «уходу на улицу» (безнадзорности) и др. [9, 11, 15, 21, 19].

Говоря о высоком значении роли матери, стоит остановиться и на влиянии отца на становление личности подростка, юноши, девушки. К сожалению, в последние годы выявляется устойчивая тенденция снижения роли отца, его значимости и влияния на воспитание и становление личности ребенка. 
Так, в фундаментальном исследовании под названием «Семья и родительство в современной России», выполненном Институтом социологии РАН, было установлено, что доля тех, кто назвал отца значимым лицом, оказавшим в процессе взросления на личность наибольшее влияние, снизилась с 41,1 \% (в старшей возрастной группе 40-44 года) до 31,8\% (в молодежной группе 16-19 лет).

Чем слабее становилась фигура отца, тем более укреплялась в сознании респондентов фигура матери. В молодежной группе (16-19 лет) доля тех, кто оценивал роль матери как самую значительную, составила 73,3\%, в то время как в старшей возрастной группе (40-44 года) таких было 61,9\% [14].

В этом исследовании, правда, имеется один существенный методологический недостаток. С ответами современной молодежи о роли отца в их становлении сравниваются ответы взрослых 40-летних людей. И на этом основании делаются выводы о том, дескать, как было раньше и как стало теперь. С психологической точки зрения, однако, вовсе не факт, что ответы 40-летних взрослых и ответы этих же респондентов на этот же вопрос, но более двадцати лет назад, т. е. в возрасте 16-19 лет - совпали бы. Ретроспективные оценки чаще всего отличаются от оценок непосредственных. И дело здесь даже не просто в элементарном забывании. А дело в том, что отсроченные, отдаленные оценки и представления о значимых и любимых людях, как правило, являются более положительными, чем оценки непосредственные «здесь и сейчас». Тем более, когда, именно как в этом случае, мы говорим о людях, которые уже давно распрощались с подростковым, юношеским максимализмом и бунтарством.

Несмотря на сказанное, все-таки мы должны констатировать, что роль и влияние матери и отца не равнозначны. Кроме того, следует подчеркнуть, что влияние родительской семьи - это не просто влияние родителей. Это именно влияние семьи. Семьи, как социального организма, как системы. Семья представляет собой систему взаимодействующих элементов, где не только родители влияют на детей, но и дети на родителей $[3,18]$. В результате этого взаимодействия, хотим подчеркнуть мы, и появляется новая реальность под названием «семья». И эта реальность такова, что совокупность элементов ее составляющих не равна целому. Это системное целое - «семья» - больше, чем только ее составляющие элементы: родители и дети. Это новое системное качество, или, если угодно, - новый организм. Мне почему-то кажется, что нечто похожее имел в виду и когда-то сформулировал, но только в гораздо более возвышенном стиле, великий Чарльз Диккенс [2] в своем романе «Николас Никльби», что семья - это не просто люди, в жилах которых течет одна кровь. Семья - это люди, за которых эту кровь ты готов отдать. 


\section{Организация исследования, выборка и методики}

Масштабное исследование изучения отношения молодежи к институту семьи и семейным ценностям было организовано нами в восьми субъектах федерации России и охватывало четыре федеральных округа: Приволжский, Сибирский, Уральский, Центральный. Научные руководители исследования профессор А. А. Реан и профессор С. Б. Малых. Координатор исследования по методической части - А. Ю. Фенин, координатор исследования по организационной части - С. В. Кардаильский. Общий объем выборки составил 7000 человек. Из этой выборки на все методики и все вопросы анкеты, без пропусков, ответили 5561 человек.

Для исследования была сформирована выборка старшеклассников из больших и малых городов России, а также из сел, из полных и неполных семей, из семей с 1-2 детьми и многодетных семей.

Выборка была репрезентативной по всем основным параметрам. Возрастной состав выборки: 14 лет - 0,4\%, 15 лет - 9,1\%, 16 лет - 49,9\%, 17 лет - 37,5\%, 18 лет - 2,3\%, старше - 0,8\%.

Характеристика выборки по классам обучения: десятый класс - 57\%, одиннадцатый класс - $43 \%$.

Состав выборки по полу: женский - 57,9\%, мужской - 42,1\%.

Состав выборки по месту проживания: города с населением до 100 тысяч человек - 19,9\%, города с населением от 100 тысяч до 500 тысяч человек - $21 \%$, города с населением от 500 тысяч человек - 32,4\%, деревня или село - 18,2\%, поселок городского типа - 8,5\%.

Характеристика выборки по составу семьи: мать, двое детей - 6,5\%; мать, один ребенок - 11,3\%; мать, трое и больше детей - $2 \%$; отец, двое детей - 0,4\%; отец, один ребенок - 0,9\%; отец, трое и более детей - 0,6\%; отец, мать, двое детей - 41,5\%; отец, мать, один ребенок - 22,5\%; отец, мать, трое детей - 14,3\%.

В процессе исследования применялись: специально составленный социологический опросник, методика изучения ценностных ориентаций Ш. Шварца, методика ценностных ориентаций «Поговорки» в модификации А. А. Реана, методика семантического дифференциала, многофакторный личностный опросник FPI, методика «80 прилагательных» А. А. Реана, методика «Стили родительского поведения». В настоящей работе приводятся и обсуждаются результаты только части исследования. А именно - обсуждаются результаты по различным блокам социологического опросника, а также по методике «80 прилагательных», в части, касающейся родителей.

\section{Результаты и их интерпретация}

Ведущими ценностями в своей жизни респонденты назвали следующие: семья, любовь, здоровье. Это доминирующая тройка. Причем даже внутри 
нее «семья» занимает лидирующее положение, с большим отрывом от двух других. Семью, как наиболее значимую ценность, выбрали 72,5\% опрошенных. В то время как занимающую второе место «любовь» - 58,4\%, а находящуюся на третьем месте ценность «здоровье» - 52,4\%. В пятерку наиболее значимых вошли также такие ценности, как «друзья» $(43,6 \%)$ и «успех» $(36,1 \%)$. Другие ценности, такие как деньги, карьера, признание, работа - по числу выборов остались за пределами первой пятерки.

Таким образом, эти данные, четко фиксирующие приоритетное значение семьи в структуре жизненных ценностей молодежи, опровергают часто озвучиваемое, а иногда и агрессивно навязываемое мнение о том, что семья - это будто бы анахронизм, и что у этого института нет будущего.

Другое дело, что возникает резонный вопрос: почему при таком высоком значении семьи в структуре ценностей молодежи все-таки столь высок процент разводов в стране? И особенно среди молодежи, в первые годы брака. К обсуждению этого вопроса удобнее всего будет обратиться сейчас, и вот в каком контексте.

Как показало наше исследование, абсолютное большинство молодежи полагает, что нужно специально готовить человека к созданию семьи путем обучения семейным ценностям. Так считают $66 \%$ респондентов. Только $15 \%$ опрошенных полагают, что этого делать не надо, а еще $19 \%$ затруднились с ответом. Эти данные внушают оптимизм. Во-первых, потому, что если человек хочет, чтобы его чему-то обучали, то это недвусмысленно свидетельствует о его интересе к предмету и теме обучения. В нашем случае об интересе к теме семьи, семейной жизни. Ну а, во-вторых, оптимистичность этих данных еще и в том, что здесь есть основания для чисто прагматического, утилитарного интереса именно для психологов, а также и для педагогов. Ну, действительно, если к созданию семьи надо специально готовить, то кому же этим заниматься, как не психологам, в дружном взаимодействии с педагогами.

Оптимизм, к сожалению, несколько поубавится при знакомстве с другими данными нашего исследования. Оказалось, что только $38 \%$ респондентов считают необходимым преподавание специального курса по вопросам семьи и семейной жизни в школах. Еще $38 \%$, то есть ровно столько же, полагают, что делать этого не надо, а 24\% затруднились с ответом.

Казалось бы, налицо очевидное противоречие этих данных с ранее приведенными результатами. Да к тому же, как все это соотнести с высоким интересом к теме семьи и семейной жизни, доминированием семьи в структуре жизненных ценностей? И все-таки, противоречия здесь нет, и одни данные не отменяют значения других. Мы полагаем, что в совокупности эти результаты требуют следующей интерпретации. Да, большинство 
молодежи считает, что обучать основам семейной жизни, семейным ценностям надо. Но это обучение не может и не должно сводиться к прямому предметному обучению в школе. Основам семейной жизни учит, привитию семейных ценностей способствует, в первую очередь, сама семья, в которой человек растет и социализируется. Не случайно, поэтому, с позиций психологии семью можно называть моделью основного жизненного тренинга. Именно уклад семьи, господствующие в ней ценности, социальные позиции и установки, система взаимоотношений между членами семьи - вот то, что обучает и готовит к будущей семейной жизни.

Кстати, что касается предметно-урочного обучения. Мы полагаем, что недостаточно внимания уделяется у нас потенциалу других предметов в контексте подготовки к семейной жизни. Даже на первый взгляд понятны широкие возможности, в этом плане, таких предметов, как литература и история.

Подытоживая рассуждения на эту тему, хотелось бы подчеркнуть: мы полагаем все-таки, что в общей системе целенаправленной подготовки молодежи к успешной семейной жизни специальный предмет по семейной тематике («Этика и психология семейной жизни», «Семьеведение» или др.) совершенно необходим. Да, как один из элементов системы, но элемент крайне важный. И связано это, среди прочего, и с тем обстоятельством, что современная семья не справляется с функцией подготовки молодежи к семейной жизни, т. е. не способна в необходимой мере осуществлять семейную социализацию.

«Хотите ли Вы, чтобы Ваша будущая семья была похожа на ту, в которой Вы выросли?» - спросили мы респондентов в нашем исследовании. Только $42 \%$ из них ответили, что да, хотели бы этого. Строго отрицательно ответили на этот вопрос $34 \%$, а еще $24 \%$ выразили сомнение, затруднившись с ответом.

Таким образом, для $58 \%$ молодежи их нынешняя, родительская семья не является ориентиром и образцом. Это реальная проблема. Возможно, именно она даже является одной из причин неготовности молодежи к браку и причиной высокой статистики разводов в первые же годы супружества. Ведь если семья не является ориентиром и образцом, то где взять эти ориентиры, где научиться поведенческим образцам жизни в семье, как приобрести столь необходимые поведенческие умения и навыки? Решение этой проблемы в первую очередь предполагает, конечно, организацию работы даже не с молодежью, а с самими родителями или, что еще лучше, с семьей в целом.

Большой интерес представляет вопрос о том, кто из членов семьи наиболее повлиял на респондентов в процессе их взросления, кто оказал наибольшее влияние на их становление. Мать в этой связи назвали 57,5\% опрошенных, а отца - только 23,7\%. Остальные члены семьи - дедушка, бабушка, старший брат/сестра - получили незначительное количество выборов. 
Высокое влияние матери на становление личности - факт, безусловно, отрадный. Однако настораживает, что отцы проигрывают со слишком большим «счетом». Психологически это, вероятно, объясняется большей эмоциональной близостью матери к детям. Но также представляется, что значительную роль играет здесь элементарный временной фактор. Отцы, как правило, проводят с детьми значительно меньше времени, чем матери. В современных условиях многие из них подрабатывают на второй работе. Более того, как нам говорили в ходе выборочных интервью, многие отцы работают вахтовым методом, уезжая на две недели каждый месяц в другие города и регионы. В связи с наличием такой тенденции в снижении роли отца стоит однозначно приветствовать возникающие в России общественные движения и инициативы, направленные на повышение роли отца в семейном воспитании. Психологическое сообщество только выиграет, если вовремя присоединится к этим движениям и окажет им профессиональную психологическую поддержку.

Мы уже отметили выше, что влияние, как дедушек, так и бабушек на становление личности в ходе взросления отметило лишь незначительное число респондентов. Интересным, однако, представляется тот факт, что приоритет и здесь принадлежит женскому полу - бабушек назвали 8,2 \% опрошенных, а дедушек почти в два раза меньше - 4,3\%.

Говоря об отношении к гражданским бракам, $54 \%$ респондентов сказали, что «это нормально», 17\% считают, что «это недопустимо», и $29 \%$ затруднились с ответом. Однако отношение к рождению детей вне зарегистрированного брака уже не столь одобряемо. Нормальным явлением считают рождение детей вне брака только $35 \%$, столько же (35\%) полагают это недопустимым, и опять же $29 \%$ затруднились с ответом. Конечно, интересно было бы исследовать гендерные различия в ответах на оба этих вопроса. Гипотетически мы предполагаем, что ответы юношей будут отражать более терпимую позицию, как на первый, так и на второй вопрос, а ответы девушек будут менее терпимыми и более негативными. Проведение такого анализа гендерных различий по всей выборке в настоящее время нами предпринимается.

Что же, по мнению респондентов, является основной причиной создания семьи? Первое место, со значительным отрывом от других названных причин, занимает «любовь» (65\%). Вторая по значимости причина - «взаимопонимание» (18\%). На третьем месте - «рождение и воспитание детей» (6\%). Другие причины набрали еще меньшее количество выборов, в пределах 2-3\%.

Коррелируют с этими данными и представления респондентов о том, каковы главные условия благополучного брака. Первое место опять 
занимает «любовь». Второе место - «взаимная поддержка». Третье место - «умение идти на компромиссы».

Показательно, что подавляющее число респондентов считают наличие семьи обязательным условием счастья (68\%). С этим не согласны $21 \%$ опрошенных, и еще $12 \%$ затруднились с ответом. Мы считаем эти данные, конечно, отрадными. Ведь вопрос был поставлен в категоричной форме - является ли семья обязательным условием счастья. И на это $68 \%$ старшеклассников определенно отвечают «да». При этом ответ «нет» ведь не исключает семью из списка условий счастья, он только исключает ее из обязательного условия счастья.

В связи с постоянно обсуждаемыми на всех уровнях проблемами, связанными с демографической ситуацией в стране, интересно было посмотреть, сколько детей планируют иметь в своей будущей семье респонденты. Как оказалось, иметь одного ребенка планируют 15\% опрошенных, двоих - 49\%, троих - 39\%, более трех - 8\%, ни одного - $9 \%$.

Следует прокомментировать тот факт, что $9 \%$ не хотят иметь детей вообще. В целом это могло бы вызвать удивление. Но в данном исследовании эта цифра вполне закономерна, ведь 7\% респондентов заявили, при ответе на другой вопрос, что они вообще не планируют создавать семью. Относительно других цифр можно сказать, что они не вполне соответствуют реальной статистике. Семьи с тремя детьми в реальности не так распространены, а семей с одним ребенком, напротив, значительно больше. Большинство семей в России имеют одного ребенка или двоих детей. Если репродуктивные установки, озвученные респондентами в этом исследовании, будут в действительности реализованы, то это внесет определенный позитивный вклад в современную демографическую ситуацию.

В ходе исследования, по методике «80 прилагательных» А. А. Реана, был получен список наиболее популярных характеристик, которыми старшеклассники описывают своих родителей. Эти обобщенные портреты матери и отца оказались полностью, абсолютно положительными. То есть они не содержали ни одной негативной характеристики. Этот факт, на наш взгляд, более чем отрадный. И имеет большое практическое значение. По крайней мере, эти данные свидетельствуют о том, что разговоры о кризисе взаимоотношений между детьми и родителями сильно преувеличены. Или конфликт между ними носит не глубинно психологический, а поверхностный, зачастую даже и просто показной характер. Установленный факт исключительно позитивного восприятия личности собственных родителей создает хорошие основания для позитивных отношений на поведенческом уровне. Возможно, эти слова прозвучат слишком афористично, но я убежден, что очень часто мы оцениваем поступки не по их реальному содержанию, а по тому, как мы относимся 
к человеку, их совершившему. Пусть это и не всегда так, но тенденция такая, конечно, существует.

Несмотря на общую социально-перцептивную картину, естественно, материнский и отцовский портреты отличались друг от друга по конкретным качествам. Назовем те общие качества, которые одинаково часто употребляются в описаниях, как отца, так и матери: добрый, надежный, заботливый, ответственный, семейственный, умный.

Дифференцированно портреты матери и отца, по первой десятке наиболее часто называемых респондентами качеств, выглядят следующим образом.

Мать, по оценке респондентов, в первую очередь: заботливая, добрая, аккуратная, ласковая, искренняя, семейственная, надежная, человечная, ответственная, умная. Как видим, большинство дескрипторов отражают эмоциональные и моральные качества. Если рассмотреть их по классам отношений (например, по В. Н. Мясищеву или Б. Г. Ананьеву), то большинство дескрипторов связано с характеристикой отношений к другим людям. Существенно меньше характеристик, связанных с отношением к делу, и совсем нет - с отношением к себе.

Отец, по оценке респондентов, в первую очередь: добрый, авторитетный, заботливый, надежный, веселый, семейственный, умный, мудрый, ответственный, искренний. Большинство дескрипторов и в этом случае отражают эмоциональные и моральные качества. Но при этом несколько увеличивается вес когнитивных составляющих портрета.

С интересом можно посмотреть и на анти-топ качеств. Это те качества, которые не характерны для представлений старшеклассников о своих родителях, качества, которые реже всего упоминаются в родительских портретах. Для отца, например, такими не характерными качествами, по мнению респондентов, являются: завистливый, глупый, трусливый, бездушный, лживый. А для матери в анти-топ качеств входят: глупая, бездушная, завистливая, неблагодарная, лживая. Список, как видим, похож. И все эти качества в обоих случаях, и относительно отца, и относительно матери, упоминаются в описаниях реже всего.

Тенденция, однако, такова, что в относительном выражении эти негативные качества в случае с отцом имеют больший вес, чем в случае с матерью. Иначе говоря, негативные дескрипторы в портретах отца и матери могут иметь одинаковое низкое ранговое место, но при этом разный вес в процентном выражении. Так, например, дескриптор «глупый», входящий в анти-топ самой непопулярной пятерки качеств, в портрете матери имеет вес $2 \%$, а в портрете отца - $5 \%$. Дескриптор «лживый» в портрете матери имеет вес $2 \%$, а в портрете отца - $6 \%$, такое же соотношение по характеристике «бездушный» - вес 2 \% в портрете матери, против 6\% в портрете отца. 
С сожалением мы вновь должны констатировать, что отцы опять «проигрывают» матерям. Почему респонденты чаще видят негативные качества именно у отцов? Отцы, в самом деле, хуже (пусть и в небольших пределах 5-6\%)? Или дети предъявляют им более жесткие требования, задают более высокие стандарты? Или с отцами чаще складываются более негативные или менее доверительные отношения? А эти негативные отношения, как хорошо известно в психологии, детерминируют и негативное восприятие личности другого. Ответы на эти вопросы, думается, могут оказаться различными в каждом конкретном случае, в каждой конкретной семье. Однако, что ясно уже сейчас, практической психологии семьи и детства, психологии семейного консультирования важно обратить особое внимание на проблему отцовства. А затем и поспособствовать привлечению к вопросам отцовства внимания всего общества.

\section{Литература}

1. Андреева Т. В. Психология семьи. - СПб., 2014.

2. Диккенс Ч. Жизнь и приключения Николаса Никльби // Диккенс Ч. Собрание сочинений. - Т. 6. - М., 1958.

3. Кайл P. (Kail R.) Тайны психики ребенка. - М., 2002.

4. Кон И. С. Психология ранней юности. - М., 1989.

5. Конан Дойл А. Письма // Биография. - 2012. - № 9. - С. 74.

6. Крайг Г. (Craig G.) Психология развития. - СПб., 2000.

7. Кухтевич Т. Н. Молодежь России - 97: мозаика рубежа века // Молодежь-97: надежды и разочарования. - М., 1997. - С. 6-15.

8. Психология человека от рождения до смерти / Под ред. А. А. Реана. - М., 2015.

9. Реан А. А. Психология личности. - СПб., 2013.

10. Реан А. А., Москвичева Н. Л. Подросток и семья // Психология подростка / Под ред. А. А. Реана. - СПб., 2007. - С. 203-233.

11. Ремшмидm X. (Remschmidt H.) Подростковый и юношеский возраст. - М., 1994.

12. Росстат, Россия в цифрах, 2015 //URL: http://www.gks.ru/bgd/regl/b15_11/ IssWWW.exe/Stg/d01/05-07.htm

13. Семенов В. Е. Ценностные ориентации современной молодежи // Социологические исследования. - 2007. - С. 37-43.

14. Семья и родительство в современной России. - М., 2009.

15. Семья: психология, педагогика, социальная работа / Под ред. А. А. Реана. - М., 2010.

16. Собкин В. С., Кузнецова Н. И. Российский подросток 90-х: движение в зону риска. - М., 1998. 
17. Ясюкова Л. А. Сравнительный анализ жизненных ценностей старшеклассников и их родителей // Преемственность поколений: диалог культур. - СПб., 1996. - С. 112-113.

18. Parke R. D., Buriel R. Socialization in the family: Ethnic and ecological perspectives // Handbook of child psychology / W. Damon (Ed.). - V. 3. - New York, 1998.

19. Specht W. (Hg). Die Gefahrliche strasse. Jugendkonflikte und Stadtteilarbeit. - Bielefeld, 1991.

20. Thornton A. Changing attitudes toward family issues in the United States // Journal of Marriage and the Family. - 1989. - 51. - pp. 873-893.

21. Understanding aggressive behavior in children. - New York, 1996.

22. Whitbourne S. K. The me I know: A study of adult development. - New York, 1986.

\section{References}

1. Andreeva T. V. Psikhologiya sem'i [Family psychology]. St. Petersburg, 2014.

2. Dickens Ch. The Life and Adventures of Nicholas Nickleby. In: Sobranie sochinenii [Collected works]. Moscow, 1958, V. 6.

3. Kail R. Tainy psikhiki rebenka [Secrets of a child's psyche]. Moscow, 2002.

4. Kon I. S. Psikhologiya rannei yunosti [The psychology of early adolescence]. Moscow, 1989.

5. Conan Doyle A. Letters. In: Biografiya [Biography]. 2012, no. 9, p. 74.

6. Craig G. Psikhologiya razvitiya [Developmental psychology]. St. Petersburg, 2000.

7. Kukhtevich T. N. The young people of Russia - 97: a mosaic of the turn of the century. In: Molodezh'-97: nadezhdy i razocharovaniya [The young people of Russia - 97: hopes and disappointments]. Moscow, 1997, pp. 6-15.

8. Rean A. A. (ed.) Psikhologiya cheloveka ot rozhdeniya do smerti [Human psychology from birth till death]. Moscow, 2015.

9. Rean A. A. Psikhologiya lichnosti [Personality psychology]. St. Petersburg, 2013.

10. Rean A. A., Moskvicheva N. L. An adolescent and a family. In: Psikhologiya podrostka [The adolescent's psychology]. St. Petersburg, 2007, pp. 203-233.

11. Remschmidt H. Podrostkovyi i yunosheskii vozrast [Adolescent and youth age]. Moscow, 1994.

12. Russian Federal State Statistics Service: Russia in Figures - 2015. [Online]. Available at: http://www.gks.ru/bgd/regl/b15_11/lssWWW.exe/Stg/ d01/05-07.htm

13. Semenov V. E. Value orientations of modern young people. Sotsiologicheskie issledovaniya - Sociological Research, 2007, pp. 37-43 (in Russian). 
RUSSIAN PSYCHOLOGICAL JOURNAL・ 2017 VOL. 14 \# 1

14. Sem'ya i roditel'stvo $v$ sovremennoi Rossii [The family and parenthood in contemporary Russia]. Moscow, 2009.

15. Rean A. A. (ed.) Sem'ya: psikhologiya, pedagogika, sotsial'naya rabota [The family: psychology, pedagogy, and social work]. Moscow, 2010.

16. Sobkin V. S., Kuznetsova N. I. Rossiiskii podrostok 90-kh: dvizhenie v zonu riska [A Russian teenager in the 90s: towards a risk zone]. Moscow, 1998.

17. Yasyukova L. A. A comparative analysis of life values in senior pupils and their parents. In: Preemstvennost' pokolenii: dialog kul'tur [Intergenerational continuity: the dialogue of cultures]. St. Petersburg, 1996, pp. 112-113.

18. Parke R. D., Buriel R. Socialization in the family: Ethnic and ecological perspectives. In: Damon W. (ed.) Handbook of child psychology, V. 3. New York, 1998.

19. Specht W. (Hg). Die Gefahrliche strasse. Jugendkonflikte und Stadtteilarbeit. Bielefeld, 1991.

20. Thornton A. Changing attitudes toward family issues in the United States. Journal of Marriage and the Family, 1989, 51, pp. 873-893.

21. Understanding aggressive behavior in children. New York, 1996.

22. Whitbourne S. K. The me l know: A study of adult development. New York, 1986. 